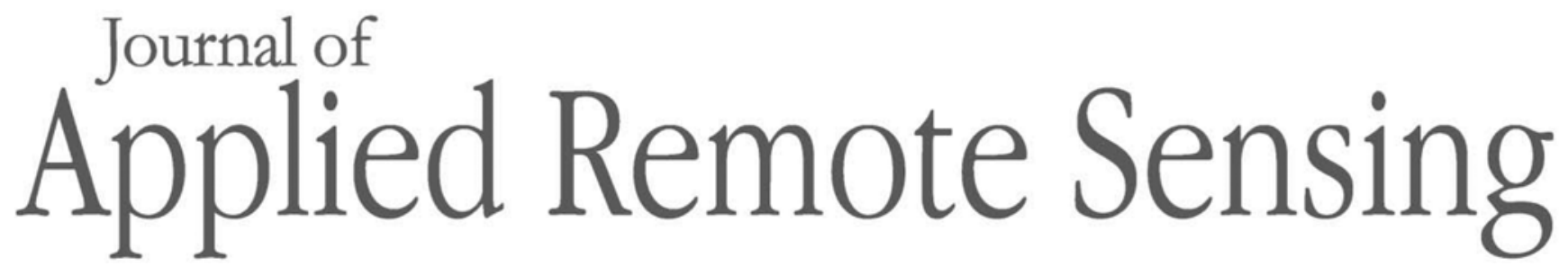

RemoteSensing.SPIEDigitalLibrary.org

\title{
Analysis of aerosol transport over southern Poland in August 2015 based on a synergy of remote sensing and backward trajectory techniques
}

\author{
Artur Szkop \\ Aleksander Pietruczuk
}




\title{
Analysis of aerosol transport over southern Poland in August 2015 based on a synergy of remote sensing and backward trajectory techniques
}

\author{
Artur Szkop* and Aleksander Pietruczuk \\ Polish Academy of Sciences, Institute of Geophysics, Warsaw, Poland
}

\begin{abstract}
Lufft's CHM 15k "Nimbus" ceilometer and a collocated Cimel sunphotometer were used, in tandem with satellite data, to observe the transport of atmospheric aerosols over Raciborz, Poland, during an exceptionally warm month of August 2015. Two distinct periods are identified: increased aerosol optical thickness (AOT) values, exceeding 0.65, during August 6 to 13 concurrent with the planetary boundary layer elevated up to $\sim 2.5 \mathrm{~km}$ and thin aerosol layers up to $7 \mathrm{~km}$ above ground visible from August 25 to 27. A newly developed scheme for backward air mass trajectory analysis is employed. The scheme utilizes satellite data on thermal anomalies as well as multiangle imaging of aerosol clouds. The obtained retrievals provide evidence that aerosols of biomass burning type were present during the first period, originating from a strong episode of wildfires in Ukraine. Moreover, satellite AOT data from the MODIS instrument show that a significant part of the observed aerosol was accumulated during transport between the region of intense biomass burning and the receptor, Raciborz. The same analysis scheme suggests that a long-range transport of biomass burning products from the United States was a source of the layers observed during the second period. (C) The Authors. Published by SPIE under a Creative Commons Attribution 3.0 Unported License. Distribution or reproduction of this work in whole or in part requires full attribution of the original publication, including its DOI. [DOI: 10.1117/1. JRS.11.016039]
\end{abstract}

Keywords: aerosols; aerosol layers; aerosol source regions; ceilometers; sunphotometer; backward trajectory analysis.

Paper 16882P received Nov. 17, 2016; accepted for publication Mar. 6, 2017; published online Mar. 20, 2017.

\section{Introduction}

Atmospheric aerosols directly influence human population as they are suspected of being responsible for more than 400,000 deaths of EU-28 citizens per year, ${ }^{1}$ predominantly by increasing the occurrence of respiratory diseases. Aerosols also affect the population indirectly as they impose an influence on Earth's climate. This influence seems to have a net cooling effect, which helps with mitigating global warming. This effect is still weakly recognized, however, and requires further studies. ${ }^{2}$ Aerosols, due to their strong temporal and spatial variability, are one of the most troublesome components in atmospheric and climate modeling. Episodes of aerosol advection are often observed over large areas as their lifetime in the atmosphere (of around few days) enables detection at a considerable distance from a source region. An observed aerosol load is usually a mixture of local and advected pollutants, which makes it difficult to identify the dominant aerosol source regions.

Saharan dust events are observed mainly in the Mediterranean ${ }^{3,4}$ and Atlantic islands. ${ }^{5,6}$ Dust may also be transported to the rest of the European mainland ${ }^{7}$ and observed over western and central Europe, ${ }^{8,9}$ sometimes along with other aerosol types, including smoke. ${ }^{10}$ Biomass burning in eastern Europe is a significant source of carbonous aerosols for the European continent. ${ }^{11}$ These kinds of aerosols are observed mainly in central and eastern Europe. ${ }^{10,12-14}$ Moreover, eastern Europe may also be a source of soil faction of the aerosols. ${ }^{15}$ Biomass burning aerosol is also known to originate from the Balkans ${ }^{16,17}$ and can even be transported from other

*Address all correspondence to: Artur Szkop, E-mail: aszkop@igf.edu.pl 


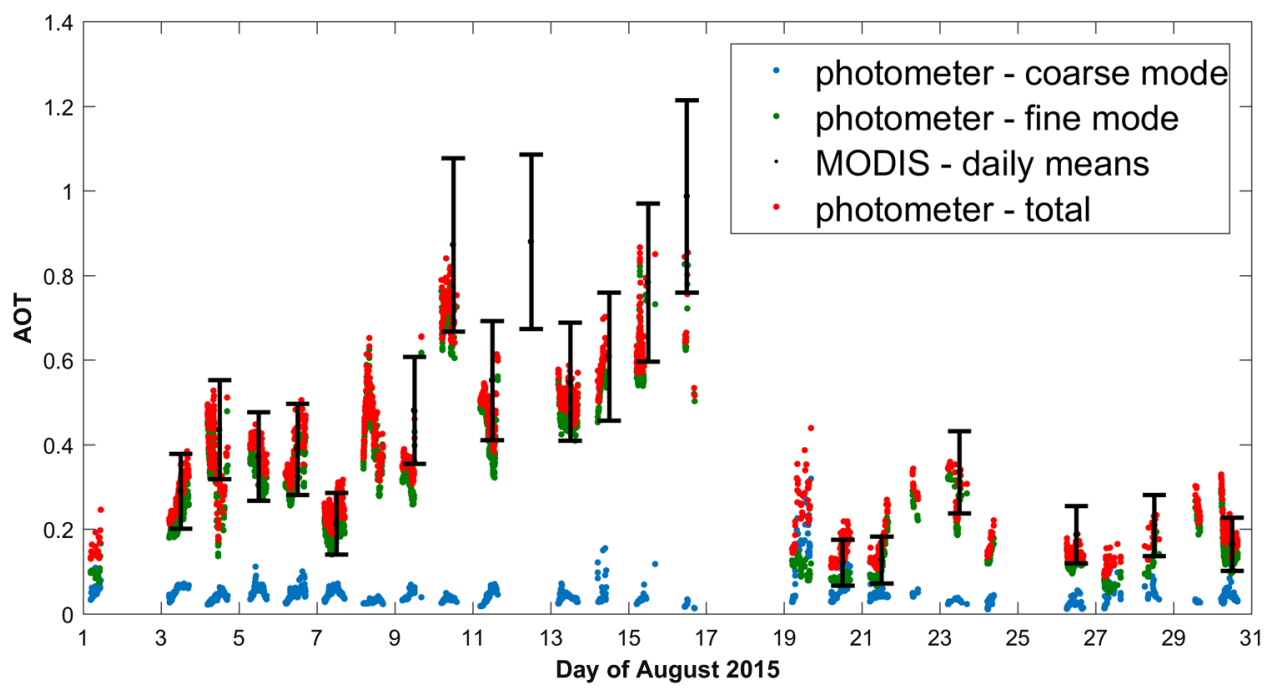

Fig. 1 Total AOT values at $500 \mathrm{~nm}$ (red) as well as AOT for coarse (blue) and fine (green) aerosol modes from consecutive CIMEL sunphotometer measurements compared to the daily means obtained MODIS (black) in Raciborz, Poland, during August 2015.

continents. ${ }^{18,19}$ Another, often spectacular, type of aerosol related to long-range transport is volcanic dust. One such event of volcanic dust originating from the Eyjafjallajökull eruption in 2010 was widely studied with various techniques, including LIDARs and sunphotometers ${ }^{20-23}$ as well as satellite-based instruments. ${ }^{24}$

In this work, we analyze an episode of high aerosol optical thickness (AOT) values coinciding with an unusually elevated planetary boundary layer (PBL) over southern Poland during August 2015 (Fig. 1). Our goal is to determine the types and source regions of aerosols observed over the station. To this end, we utilize a recently developed scheme for analyzing sunphotometer optical aerosol data supported by backward trajectories calculated based on an atmospheric model. The performance and usefulness of the scheme was previously tested on data obtained at our measurement station at Belsk, Poland. In this study, we expand the scheme to incorporate ceilometer data. This allows for vertical analysis of aerosol content with a main focus on the height of the PBL and detection of aerosol layers in the free troposphere. The scheme is applied to data obtained at an automatic (i.e., unmanned) station in Raciborz $\left(50.09^{\circ} \mathrm{N}, 18.19^{\circ} \mathrm{E}\right)$, Poland, equipped with both sunphotometer and a ceilometer. Satellite data on AOT and wildfires are then used to validate the credibility of the candidate source regions. The proposed scheme seems to be best suited for studying short- to mid-range intracontinental transport. To determine the usability of the proposed approach for a long-range aerosol transport, we analyze an event of transatlantic transport, which, while visible as thin layers in the ceilometer signals, did not significantly influence the observed columnar AOT.

\section{Instruments}

The observation site is located in Raciborz $\left(50.09^{\circ} \mathrm{N}\right.$ and $\left.18.19^{\circ} \mathrm{E}\right)$. This town, populated by more than 50,000 citizens, is located close to the so-called Moravian Gate, a depression between Sudetes and Carpathian Mountains in southern Poland. The town is relatively close to the industrial regions of Silesia in Poland and Ostrava in the Czech Republic. The observatory, although fully automated, is routinely supervised by a trained staff member. The scientific equipment comprises a tandem of sunphotometer and ceilometer instruments that are used for aerosol investigations.

Historically, ceilometers were designed for measuring the height of a cloud base. Now, laserbased instruments may also be utilized as LIDARs ${ }^{25}$ for aerosol layer observations. Although much more affordable, ceilometers have lower energy in the emitted laser pulses compared to a typical LIDAR, as they predominantly utilize low cost, diode pumped lasers. The low laser 
pulse energy translates into a relatively low signal-to-noise ratio (SNR). The Lufft's CHM 15k "Nimbus" ceilometer, operated at the Raciborz station, is a modern instrument designed as a single wavelength (1064 nm) LIDAR capable of observing aerosol layers up to $15 \mathrm{~km}$. The instrument's spatial resolution is $15 \mathrm{~m}$ (i.e., the backscattered radiation is registered in 15-m long-range gates) and the full overlap between the laser beam and the receiver's field of view is achieved at $\sim 0.4 \mathrm{~km}$. Below this level, a geometric correction is performed to compensate for the incomplete overlap, which results in low SNR, especially in the lowermost range gates.

CIMEL Sun and sky scanning photometers are used worldwide to determine aerosol's optical properties. Most of them are federated in the Aerosol Robotic Network (AERONET), ${ }^{26}$ which provides various data products, including optical thickness at several wavelengths, Angstrom exponent, coarse-to-fine ratio and aerosols' microphysical parameters. Detailed descriptions of the instrument, the network, data products, and the data processing scheme can be found in literature. ${ }^{26-30}$ In this work, we use AERONET level 2.0 data collected at the Raciborz station.

\section{Methodology}

Statistical analysis of air mass backward trajectories was used to find possible aerosols' source regions. Five-day-long backward trajectories (with a resolution of $1 \mathrm{~h}$ ) were computed with the HYSPLIT mode ${ }^{31}$ using $0.5 \mathrm{deg} \times 0.5$ deg GDAS meteorological archives. A single trajectory is a series of three-dimensional (3-D) coordinates (comprised of longitude, latitude, and height above sea level) calculated every full hour. Each such triplet of 3-D coordinates and a corresponding date and hour are later referred to as a trajectory point. The latest trajectory point (i.e., the final coordinates of the traced air mass) is defined as an endpoint. We used three trajectories per day ending at 6:00, 12:00, and 18:00 with the endpoints located over the Raciborz station (i.e., the receptor) at various altitudes. The endpoint altitudes roughly correspond to the heights at which an elevated loading of aerosol was observed in the ceilometer signals.

An analysis of the trajectories was performed based on the newly developed scheme that was applied in our previous work. ${ }^{32}$ The calculated trajectories were interpolated onto a two-dimensional (2-D) $0.5 \mathrm{deg} \times 0.5 \mathrm{deg}$ grid positioned over Europe to find possible source regions. Each grid point resides in the center of a $0.5 \mathrm{deg} \times 0.5 \mathrm{deg}$ geographical area forming a 2-D data array (in the longitude-latitude coordinate system). According to Eq. (1), the value of each cell $R_{i j}$ becomes a sum of a number of collocated trajectory points weighted by the distance $d_{i^{\prime} j^{\prime}}$ between each trajectory point $\tau_{i^{\prime} j^{\prime}}$ and the receptor (measured along the trajectory). This should be understood as a number of trajectory points residing within the cell normalized by the distances between the trajectory points and the receptor:

$$
R_{i j}=\sum_{t=1}^{T} \sum_{h=1}^{H} \sum_{i^{\prime}=1}^{I} \sum_{j^{\prime}=1}^{J} \begin{cases}d_{i^{\prime} j^{\prime}}, & i=i^{\prime} \cap j=j^{\prime} \cap A \leq A_{t}, \\ 0, & i \neq i^{\prime} \cup j \neq j^{\prime} \cup A>A_{t}\end{cases}
$$

where $I$ and $J$ are the dimensions of the grid, $i, j$ are the coordinates of a grid point, $i^{\prime} j^{\prime}$ are the coordinates of trajectory point, $t$ represents a $t^{\prime}$ th trajectory from all $T$ trajectories, and $h$ is a $h$ 'th hour out of the total trajectory length of $H$ hours. The altitude of a trajectory point is given by $A$, whereas $A_{t}$ is the threshold for the altitude. The threshold is applied to reflect the fact that only low traveling trajectories are likely to accumulate ground-emitted aerosols.

The proposed scheme presents an alternative approach when compared to the commonly used methods for statistical trajectory analysis. Both the concentration weighted trajectory ${ }^{33,34}$ and the potential source contribution function ${ }^{35}$ methods weigh every grid point value by dividing it by the number of corresponding trajectory points. This normalizes the values in the whole domain and allows for a simple, direct comparison between any two given points. At the same time, such a normalization makes the aforementioned methods insensitive to the local distribution of the directions of air advection.

A simple removal of the normalization would result in an increased density of trajectories close to the receptor site. Such a density, in the case of straight, randomly distributed trajectories, would be inversely proportional to the distance from the receptor (similarly, a mean density of points that belong to a sheath of strait lines falls proportionally to the distance from the sheath's 
cross point). The weighting of each trajectory point with the distance to its endpoint serves as a range correction that mitigates the density problem. This range correction, presented in our approach, is designed so the information on the directions of advection may be retained in the analysis while all the values (regardless of the distance from the receptor site) are of a similar order of magnitude. This allows for a straightforward qualitative analysis of the grid values (i.e., hotspots of trajectory densities, both close and far from the receptor site, are visible).

Optical data obtained by instruments onboard Terra and Aqua satellites were used to characterize the potential source regions of aerosols. Moreover, MODVOLC ${ }^{36}$ thermal anomalies were used to identify locations and scope of open fires. Thermal anomalies are observed as high-temperature pixels registered by a moderate resolution imaging spectroradiometer (MODIS) instrument onboard both the satellites. Such pixels are primarily used to investigate volcanic activity, however, they are also a good tool for monitoring of open fires, both of natural and anthropogenic origin. Additionally, data from a multiangle imaging spectroradiometer (MISR) instrument onboard the Terra satellite, were used to investigate heights of smoke clouds. ${ }^{37}$ This instrument provides pictures of Earth's surface taken by nine cameras under different view angles. A set of nine such multiangle pictures, analyzed with a specialized "MISR interactive explorer" (MINX) software package, allows determining the location and height of a smoke cloud top as well as its velocity. ${ }^{38}$

\section{Results and Discussion}

During the chosen period of August 2015, extremely elevated aerosol layers were registered at the Raciborz site. The evolution of aerosol within the PBL, including the nighttime residual layer, is depicted in Fig. 2. The PBL height reaches $\sim 2.5 \mathrm{~km}$ while additional aerosol layers up to $4 \mathrm{~km}$ are also visible in the ceilometer signal. In some cases, layers are connected to the aerosol within the PBL (e.g., August 6 and 13) or even a single continuous mixed layer up to $4 \mathrm{~km}$ is visible (e.g., August 10). This makes differentiating between PBL aerosols and free troposphere layers difficult. Moreover, separate weak aerosol layers were found up to $7 \mathrm{~km}$ above ground from August 25 to 27. An analysis of sunphotometer data suggests that two distinct periods were present. The first one is characterized by elevated values of AOT at $500 \mathrm{~nm}$ $\left(\mathrm{AOT}_{500}\right)$ when aerosol layers extended up to around $4 \mathrm{~km}$ above ground. In the second one, thin aerosol layers were observed in the free troposphere and were not measurably influencing the $\mathrm{AOT}_{500}$ values. Based on the different vertical structure and optical properties observed during both periods, we have decided to analyze the two periods separately. In both cases, the possible source regions of the layers are investigated with the aforementioned analysis of air mass backward trajectories.

\subsection{First Period-August 6 to 13, 2015}

During this period, the mean $\mathrm{AOT}_{500}$ registered at Raciborz station was $0.51 \pm 0.05$ while the annual mean for 2015 was $0.21 \pm 0.01$. The mean Angstrom exponent for the period

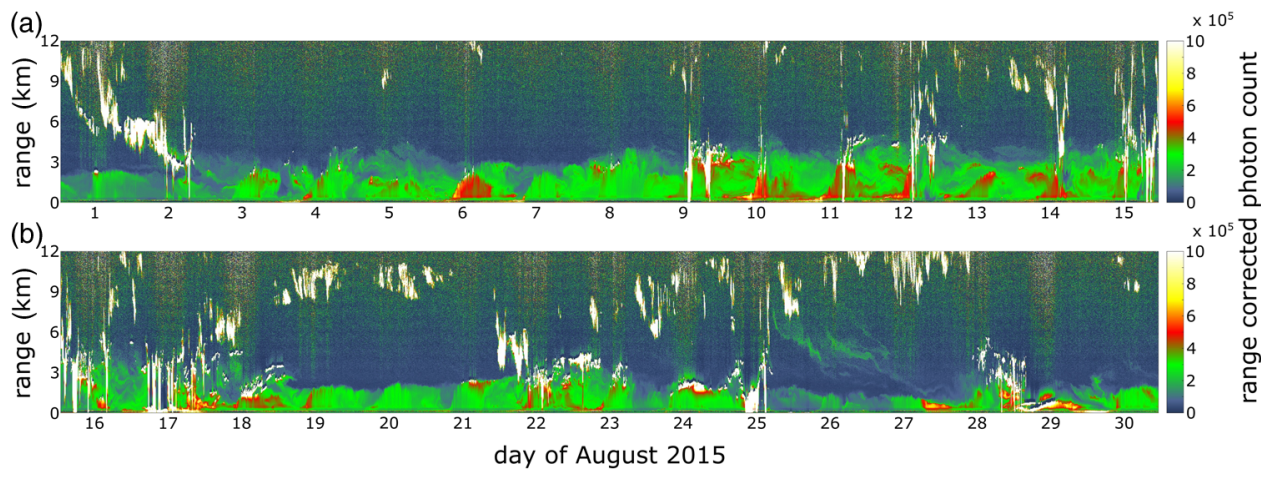

Fig. 2 Range corrected attenuated backscatter signals from CHM 15k "Nimbus" ceilometer registered during the first (a) and the second (b) part of August 2015 at the Raciborz station. White color represents clouds or fog. 
was $1.69 \pm 0.02$ while the annual mean for 2015 was $1.44 \pm 0.03$. Enlarged values of these parameters and the domination of total AOT by the fine mode component suggest an advection of urban/industrial type pollutants. ${ }^{39}$ However, the mean $\mathrm{AOT}_{500}$ value is close to the threshold for biomass burning aerosol used in our previous work. ${ }^{32}$

Possible source regions of the layers are investigated with statistical analysis of air mass backward trajectories. Five-day-long backward trajectories with the endpoints chosen at 0.5, 2, and $3.5 \mathrm{~km}$ were calculated for the considered period with the endpoints over the Raciborz station. Statistical analysis, described in the previous section, was performed to find possible source regions of the aerosols. The threshold for altitude was chosen at $1.5 \mathrm{~km}$, a height representative for the observed PBL. Range corrected density of trajectory points [Eq. (1)] for three altitudes is presented in Fig. 3. The apparent lack of continuity of some of the trajectories is the result of an altitude threshold imposed on the individual trajectory points. One hotspot of trajectory density for the lowest endpoint altitude is seen over the vicinity of the Cracow agglomeration and southern Poland. Two further hotspots are visible for the middle endpoint altitude, one spanning from southern Poland (Cracow region) through eastern Slovakia to northeastern Hungary and the second one close to the Russia-Ukraine border. There is also a trail connecting both the hotspots. In the case of the highest endpoint altitude, the first hotspot is diffused and the second one is moved in the eastern direction.

The large trajectory density in southern Poland suggests local urban/industrial influence at the lower altitudes. A similar type of aerosol may also be transported over the Carpathian Mountains from the eastern borderland of Slovakia and Hungary. This region was found in literature $^{32}$ to be a potential source of urban/industrial aerosol for central Poland. The Ukrainian hotspot is less evident. Transport of anthropogenic aerosols from the vicinity of Kiev may be expected based on the large trajectory density east of Kiev. Moreover, these regions, especially a trail connecting both the hotspots, are typical sources of biomass burning aerosols. ${ }^{11}$

To validate the possibility of a long-range aerosol transport from the Ukraine, we used MODIS instrument data. A number of high temperature pixels registered by the MODIS instrument between August 4 and 16 are presented in Fig. 4. The largest density of open fires is located in western Ukraine as well as in the southern and eastern parts of the country. A large density of trajectory points for the altitude of $3.5 \mathrm{~km}$, present in southern and eastern Ukraine, makes transport of biomass burning products to southern Poland probable. This aerosol is possibly mixed with the urban/industrial type, usually advected from the aforementioned urbanized and industrialized regions.

Additionally, an analysis of the changes in the observed $\mathrm{AOT}_{500}$ values during air mass transport between the regions, mentioned in the previous section, was performed. We have defined three regions (Fig. 4): (a) the vicinity $(0.3 \mathrm{deg} \times 0.3 \mathrm{deg})$ of the receptor site in Raciborz, (b) the region east of Cracow in Poland and eastern Slovakia, and (c) the eastern Ukraine north of the hotspot of trajectory density visible in Fig. 3. We used daily means of MODIS AOT S00 $_{\text {data }}$ (collection 6) interpolated on a regular $0.1 \mathrm{deg} \times 0.1 \mathrm{deg}$ grid. The differences in $\mathrm{AOT}_{500}$ were calculated for the advection from the aforementioned two regions (b) and (c) to Raciborz (a). Obtained frequency plots are presented in Fig. 5. The registered AOT changes in most of the cases are positive, i.e., $\mathrm{AOT}_{500}$ increased as the air mass was traveling between the considered regions. This strongly indicates that the aerosol sources were placed mainly
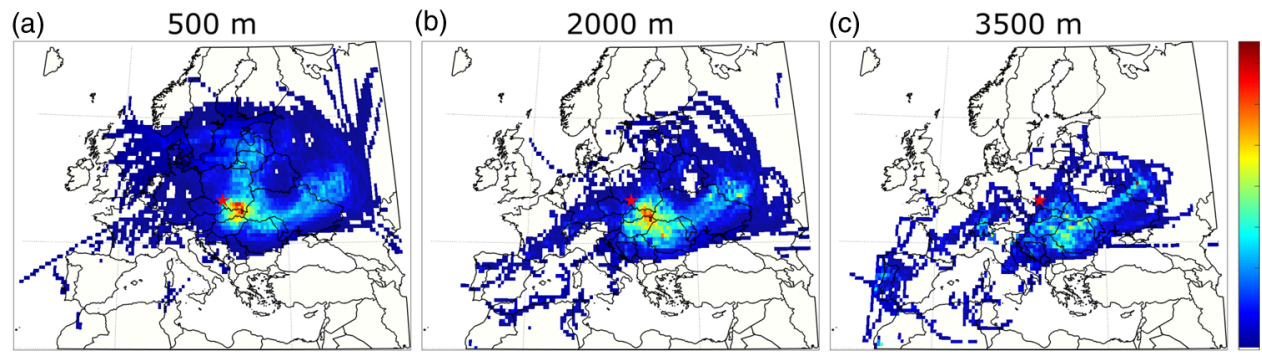

Fig. 3 Range corrected number of trajectory points [Eq. (1)] with endpoints over Raciborz $(50.087 \mathrm{~N}, 18.190 \mathrm{E})$. The three investigated endpoint altitudes are presented separately on subfigures (a), (b), and (c). The receptor site is depicted with a red star. 


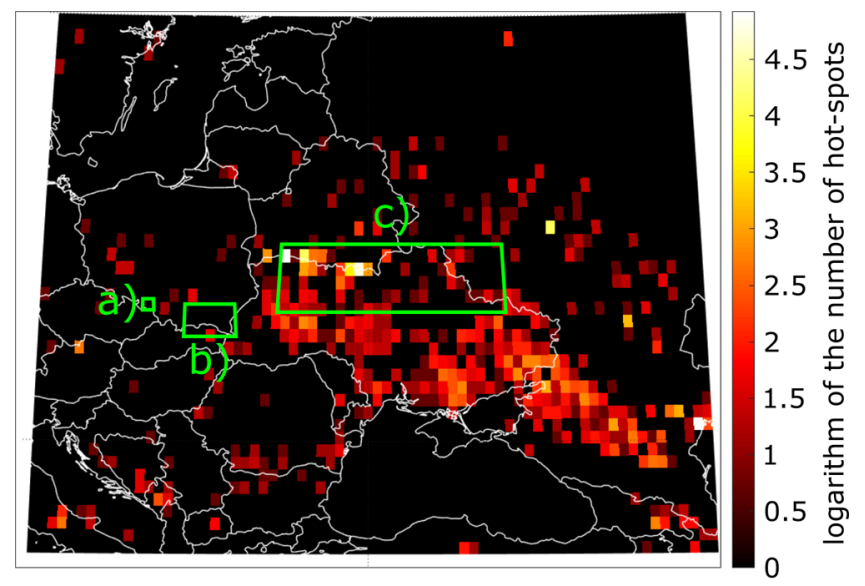

Fig. 4 Number of high temperature MODIS pixels in the period of August 4 to 16, 2015 (obtained with the MODVOLC algorithm). Note that the color scale is logarithmic for better visualization. Regions of interest are depicted with green rectangles.

between the regions retrieved from the trajectory analysis. In both cases, the distribution of the obtained $\mathrm{AOT}_{500}$ changes is multimodal (the individual modes are assumed to follow the Gaussian distribution). Moreover, a least square fit is performed and depicted in Fig. 5.

First, lowest mode is concentrated around 0.2 to 0.24 . This mode, dominant for the region (b), originating air mass becomes less noticeable in the data registered during the advection from the region (c). As the area between Cracow and Raciborz is more densely populated than the southern Ukraine, this mode is possibly associated with anthropogenic continental type aerosol.

For the second mode, an $\mathrm{AOT}_{500}$ change of $\sim 0.55$ is found for (b) $\rightarrow$ (a) transport, whereas the change is $\sim 0.45$ for $(\mathrm{c}) \rightarrow$ (a) transport. AOT $_{500}$ changes may be associated with strong emissions from the industrialized regions, between southeastern Poland and eastern Slovakia and Raciborz in the former case and the vicinity of Kiev in the latter one.

In the case of transport from the region (c), a third mode appears, concentrated around 0.65. Such an unusually high AOT $_{500}$ change must be associated with a strong emission event that occurred between the two regions. A large number of fire pixels visible in Fig. 4 over central and eastern Ukraine strongly suggests that the aerosol was of biomass burning type.

Both the second and the third mode are related to unexpected, large $\mathrm{AOT}_{500}$ registered by the MODIS instrument over Raciborz with values exceeding 0.8 on several days. The agreement between daily averaged MODIS measurements and those taken by the CIMEL sunphotometer, presented in Fig. 1, is well with $R^{2}=0.98$ but not perfect possibly due to large diurnal changes of AOT observed by the latter instrument over Raciborz.

(a)

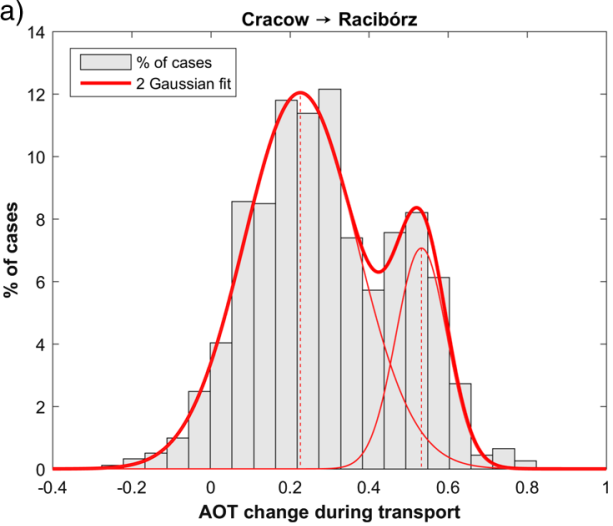

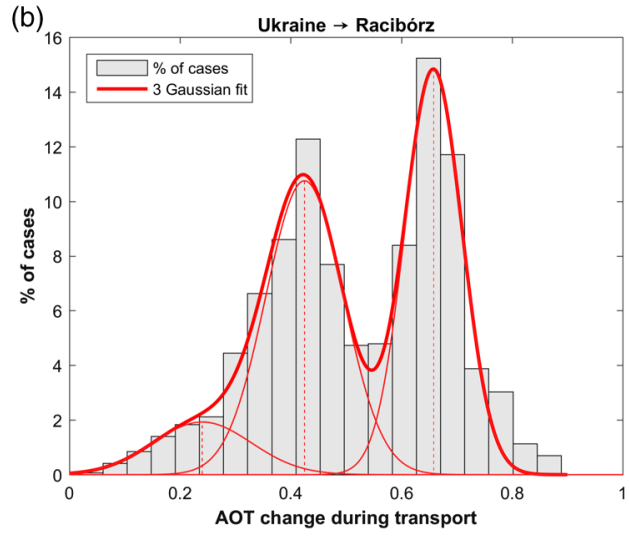

Fig. 5 The distribution of the changes in the AOT500 (based on MODIS measurements) calculated for the trajectories arriving at Raciborz. The left- and right-hand side figures correspond to the transport originating from the region (b) and (c), respectively (see Fig. 4). The sums of Gaussians are depicted by thick red lines while the thin lines represent the individual modes. 


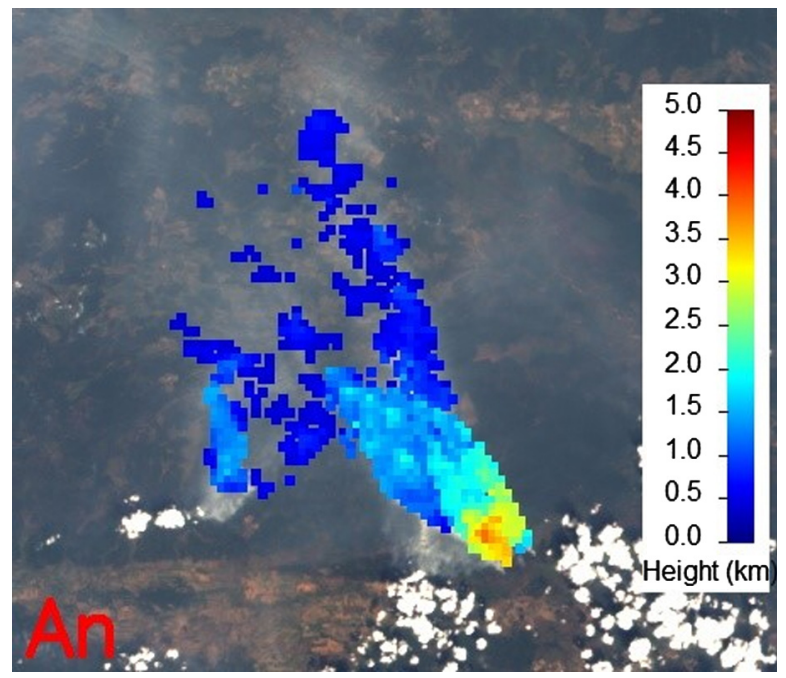

Fig. 6 An example of MINX retrieval of smoke cloud height, August 11, 2015 northwest of Kiev. The algorithm utilizes a series of nine consecutive satellite photographs taken under different angles to triangulate the height of the smoke cloud.

Although the presented analysis suggests that aerosols were transported from Ukraine to Poland, it does not explain the large altitudes related to aerosol observed by the ceilometer. To check for a possibility of long-range transport of aerosols in the free troposphere, we performed an analysis of smoke cloud heights using satellite data with the MINX software. MINX uses satellite images of the same area taken under different viewing angles to obtain cloud heights. ${ }^{38}$ A similar algorithm is routinely applied for stereoscopic retrieval of liquid water clouds, however, in the case of smoke or dust, manual operation of MINX is necessary. It is worth noting that because the MISR foot path is much smaller than the one for MODIS and MISR instruments, it provides inferior ground coverage. Nevertheless, eight orbits containing MODIS fire pixels were found and analyzed. Most of the fires were located close to the Black Sea and Azov Sea coast lines. The retrieved heights of the smoke clouds were up to $0.75 \mathrm{~km}$. In this case, biomass burning products may have been transported mainly in PBL. A few open fires were found close to the Ukraine and Belarus border with cloud heights up to $1.5 \mathrm{~km}$ and one extreme case with smoke cloud height of over $3 \mathrm{~km}$ (see Fig. 6). That fire spot was located northwest of Kiev in the area where we found a large density of trajectories. The smoke cloud, rising into the free troposphere, may be a source of the elevated aerosol load both in the PBL and above it.

\subsection{Second Period-August 25 to 27, 2015}

During this period, aerosol layers decreasing from 7 to $2.5 \mathrm{~km}$ above ground were observed. The significant height at which the layers were residing suggests long-range transport of the aerosols. Moreover, columnar aerosol optical properties during this event were close to the longtime mean, and the layer's optical thickness, calculated based on the ceilometer data, was found to be negligible compared to the columnar AOT. Nevertheless, we have decided to investigate the possibility of using the proposed scheme (without calculating the AOT changes during transport) for detecting potential source regions at long distances. To find the possible source regions, we performed an analysis of the backward trajectories similar to the one in Sec. 4.1. In this case, we applied a different threshold for trajectory point heights, namely $3 \mathrm{~km}$ above ground, to reflect the greater height at which the aerosol layers were observed. Trajectories were calculated every $6 \mathrm{~h}$ and endpoints at altitudes corresponding to the observed aerosol layers were chosen. The results are presented in Fig. 7. There are two regions of larger trajectory density, one spanning form the France coast and Biscay to the eastern coastline of Canada and the second one covering central and northwestern parts of the United States. The high threshold for altitudes results in visible discontinuities of the trajectories. 


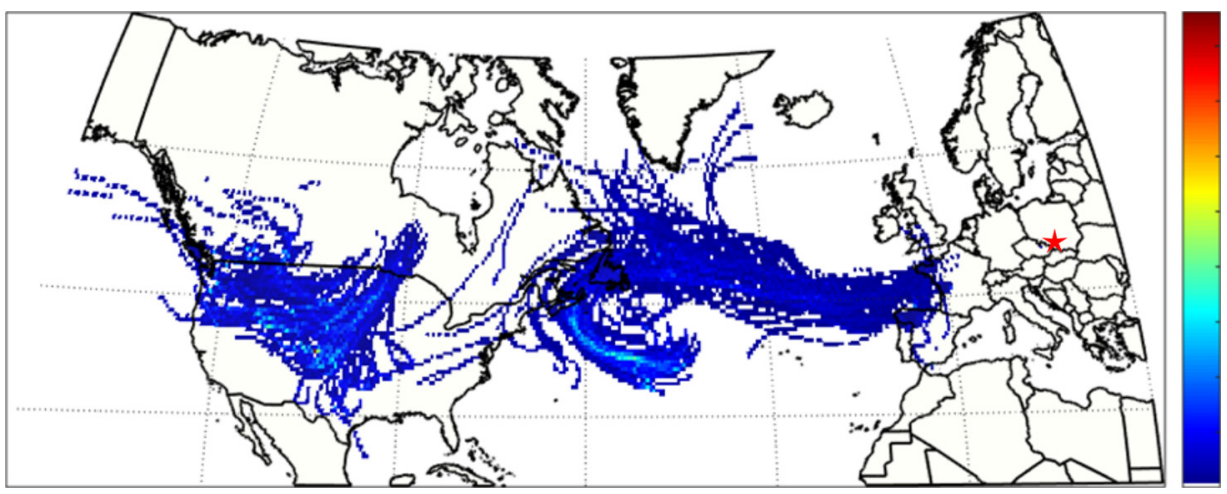

Fig. 7 Range corrected number of trajectory points [Eq. (1)] with endpoints over Raciborz $\left(50.087^{\circ}\right.$ $\left.\mathrm{N}, 18.190^{\circ} \mathrm{E}\right)$. The receptor site is depicted with a red star.

The region above the Atlantic reflects the predominant path of air mass transport during the period. There are few possible sources of biomass burning or anthropogenic aerosols in the region. However, a limited contribution from the maritime aerosol originating from the northern Atlantic is possible. ${ }^{40}$ The second region, located over land, could be a strong source of both industrial and biomass burning pollutants, which are, in some cases, observed over Europe. ${ }^{18,19}$ To check for such possibility, we performed analysis of MODVOLC thermal anomalies over the United States. The results are presented in Fig. 8. Moreover, similar to the previous chapter, an analysis of smoke cloud height was performed.

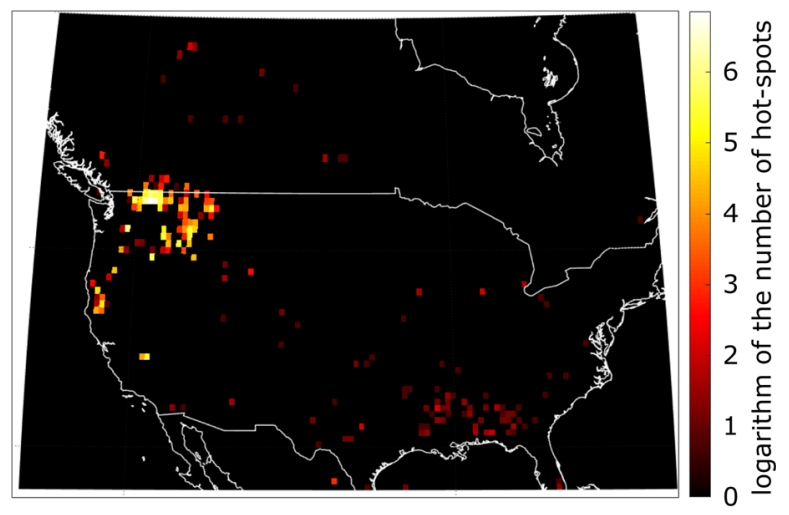

Fig. 8 Logarithm of the number of high-temperature pixels in the period of August 21 to 27, 2015 obtained from the MODVOLC algorithm.

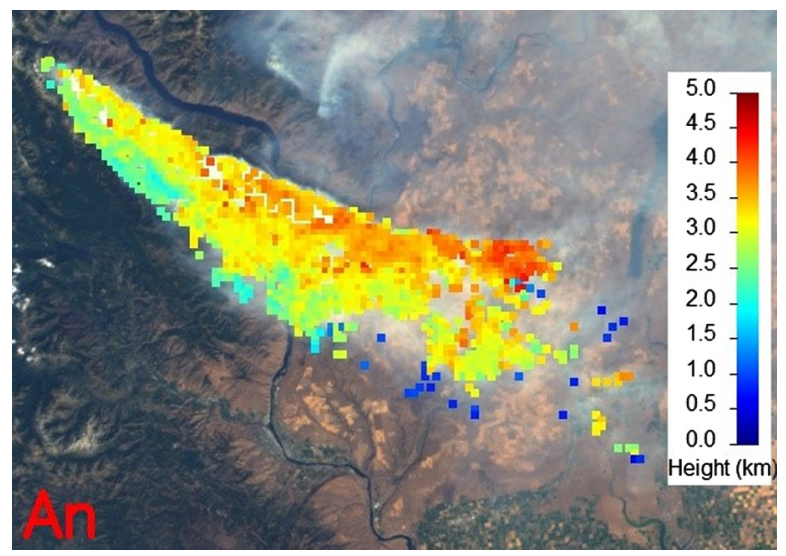

Fig. 9 An example of MINX retrieval of smoke cloud height, August 22, 2015 in the northwestern part of US in Washington State. 
The largest density of MODVOLC pixels is located in the northwestern part of the US in Washington, close to the Canadian border. According to the trajectory analysis, this region is a possible source of biomass burning products observed as a free troposphere aerosol layer over Raciborz. Stereoscopic analysis of smoke cloud heights revealed a number of high altitude open fires. In most of the cases, smoke cloud heights were at $\sim 2.5$ to $3 \mathrm{~km}$ above sea level. The largest registered smoke cloud height was at around $4 \mathrm{~km}$ above sea level (the fire source was located in a mountainous area elevated up to $2 \mathrm{~km}$ a.s.l., see Fig. 9). The smoke injected into the free troposphere was transported along with the western circulation, which enabled observation over Raciborz.

\section{Conclusions}

Aerosol layers up to $4 \mathrm{~km}$ were observed at Raciborz in August 2015. The unusually high temperatures, present during the reported period, led to the PBL rising above $2.5 \mathrm{~km}$, e.g., August 13. Such heights are rarely seen in the data over Poland. ${ }^{41}$ Aerosol layers present within and above the PBL are suspected to have a remote source. The synergy between ground-based and remote sensing instruments (a ceilometer and a sunphotometer) allowed identifying two separate periods. The first one was characterized by an unusually high PBL while the AOT was larger than the longtime mean. In the second period, a number of high aerosol layers in the free troposphere were observed. Statistical analysis of air mass backward trajectories allowed for an estimation of the potential source regions of the observed aerosol layers. This is an extension of our previous investigations ${ }^{32}$ with the analysis of aerosol columnar properties, e.g., demonstration that the northwestern US is likely a source region of the aerosol layer observed in the free troposphere of August 25 to 27. In the case of the first period, most of the potential source regions are located toward east and south of Poland slightly expanding for higher altitudes of the aerosol layer.

The addition of satellite-based data allowed characterizing the previously estimated source regions and their predominant aerosol type. The analysis of MODVOLC hot pixels revealed the occurrence of widespread wildfires within the regions of large trajectory density, strongly indicating them to be the sources of biomass burning aerosols. Additional analysis done with MINX software provided information about smoke cloud heights at the regions with the largest hot pixels density. The detected height of 3 to $4 \mathrm{~km}$ a.s.l. shows that aerosol injected into the free troposphere in the US may be detected as a separate aerosol layer over southern Poland. Similarly, smoke cloud height over $3 \mathrm{~km}$ a.s.l detected west of Kiev validates the possibility of a transport of biomass burning products over PBL. In fact, we suspect that most of the aerosols immediately over PBL (i.e., within a layer between $2.5 \mathrm{~km}$ to $4 \mathrm{~km}$ ) have a biomass burning origin. On the other hand, most of the smoke cloud heights detected over Ukraine were within PBL, thus, another injection mechanism into a free troposphere may have played a role. One possibility is a two-way aerosol exchange between the PBL and the free troposphere enabled through the eddy driven entrainment. ${ }^{42}$ Moreover, convective streams within the PBL are capable of transporting the ground emitted aerosols upward toward the PBL top when the fine aerosol particles remain suspended in the free troposphere while the PBL decays during the night.

Nevertheless, most of the aerosols were probably transported in the PBL or within the residual layer. We therefore suspect that the aerosol in the PBL is of a mixed type, composed mainly of biomass burning products, anthropogenic emissions, and continental background. Trajectory analysis indicated that a region southeast of Cracow is a potential aerosol source for lower layers while higher layers may originate from eastern Slovakia and northern Hungary. These densely populated and industrialized regions in Poland and in southeastern Slovakia may be sources of anthropogenic aerosols. However, the analysis of differences in AOT between this region and the receptor site in Raciborz indicates local emissions as a significant aerosol source. Positive gradient of AOT values, calculated along the trajectories, show that aerosol was loaded into the air mass between the mentioned region and the receptor. Moreover, similar analysis done for the vicinities of Kiev and Raciborz also indicates positive gradients of AOT values, which shows that air mass was saturated by biomass burning aerosol between Kiev and Raciborz. This Ukrainian territory was affected at that time by a large number of wildfires, see MODVOLC analysis. 
The performed analysis of AOT gradients shows some limitations of the applied trajectory analysis. It seems that the aerosol sources are not exclusive to the largest densities of trajectories. A strong point emitter situated between an estimated potential source region and the receptor may lead to a false positive. Local aerosol sources should also be taken into account especially when the vicinity of the receptor is strongly industrialized and densely populated. This may be seen in the analysis of AOT gradients between Raciborz and the region southeast of Cracow (Fig. 5).

This work aims to supplement and extend our previous efforts ${ }^{32}$ by accounting for columnar distribution of aerosol layers as well as the changes in aerosol loading during the transport between the source regions and the receptor. This requires a simultaneous use of sunphotometer-, ceilometer-, and satellite-derived data. These data may be obtained automatically and do not require continuous supervision by a trained staff member on the measurement station. Moreover, the combined cost of a sunphotometer and a ceilometer remains low when compared to a LIDAR system. It should be noted, however, that the deliverables of the proposed scheme should not be considered to be a substitute for those obtained with a full-fledged, multichannel LIDAR system that allows for direct retrieval of high resolution aerosol optical and microphysical properties in the air column.

The presented case study shows that combining measurements of a collocated ceilometer and a sunphotometer may prove useful for identifying the source and type of atmospheric aerosols. The complete analysis of aerosol advection must include both the source region recognition as well as the study on modification during transport. Such knowledge is important for the forecasting of aerosol concentration and may also be used in the efforts to reduce the exposure of the population to aerosol rich air.

\section{Acknowledgments}

This work was supported by the Polish National Science Centre under Grant No. NCN 2013/09/ B/ST10/03553. Authors acknowledge AERONET-Europe for providing calibration service. AERONET-Europe is part of ACTRIS-2 project that received funding from the European Union (H2020-INFRAIA-2014-2015) under Grant Agreement No. 654109. Authors also acknowledge the MODIS and MISR mission scientists and associated NASA personnel for the production of the data used in this research effort. The MODIS data were obtained from the Level-1 and Atmosphere Archive \& Distribution System (LAADS) while the MISR data were obtained from the NASA Langley Research Center Atmospheric Science Data Center (ASDC). The authors have no relevant financial interests in the manuscript and no other potential conflicts of interest to disclose.

\section{References}

1. European Environment Agency, "Air quality in Europe-2014 report," EEA Report No. 5/ 2014 (2014).

2. IPCC, "Climate change 2013 the physical science basis," Cambridge University Press (2014).

3. A. Papayannis et al., "Systematic LIDAR observations of Saharan dust layers over athens, greece in the frame of earlinet project (2004-2006)," Ann. Geophys. 27(9), 3611-3620 (2009).

4. J. Pey et al., "African dust outbreaks over the mediterranean basin during 2001-2011: PM 10 concentrations, phenomenology and trends, and its relation with synoptic and mesoscale meteorology," Atmos. Chem. Phys. 13(3), 1395-1410 (2013).

5. C. Córdoba-Jabonero et al., "Synergetic monitoring of Saharan dust plumes and potential impact on surface: a case study of dust transport from Canary Islands to Iberian Peninsula," Atmos. Chem. Phys. 11(7), 3067-3091 (2011).

6. D. Müller et al., "Vertical profiles of pure dust and mixed smoke-dust plumes inferred from inversion of multiwavelength Raman/polarization LIDAR data and comparison to AERONET retrievals and in situ observations," Appl. Opt. 52(14), 3178-3202 (2013).

7. P. Israelevich et al., "Predominant transport paths of Saharan dust over the mediterranean sea to Europe," J. Geophys. Res. Atmos. 117(D2), D02205 (2012). 
8. A. Papayannis et al., "Systematic LIDAR observations of Saharan dust over Europe in the frame of earlinet (2000-2002)," J. Geophys. Res. Atmos. 113(D10), D10204 (2008).

9. J. P. Chaboureau et al., "Long-range transport of Saharan dust and its radiative impact on precipitation forecast: a case study during the convective and orographically-induced precipitation study (COPS)," Q. J. R. Meteorol. Soc. 137(S1), 236-251 (2011).

10. A. Pietruczuk and A. Chaikovsky, "Variability of aerosol properties during the 2007-2010 spring seasons over central Europe," Acta Geophys. 60(5), 1338-1358 (2012).

11. F. Barnaba et al., "An important fingerprint of wildfires on the European aerosol load," Atmos. Chem. Phys. 11(20), 10487-10501 (2011).

12. N. Y. Chubarova, "Seasonal distribution of aerosol properties over Europe and their impact on UV irradiance," Atmos. Meas. Tech. 2, 593-608 (2009).

13. T. Mielonen et al., "Biomass burning aerosols observed in eastern finland during the russian wildfires in summer 2010-part 2: remote sensing," Atmos. Environ. 47, 279-287 (2012).

14. A. Pietruczuk, "Short term variability of aerosol optical thickness at Belsk for the period 2002-2010," Atmos. Environ. 79, 744-750 (2013).

15. W. Birmili et al., "A case of extreme particulate matter concentrations over central Europe caused by dust emitted over the southern Ukraine," Atmos. Chem. Phys. 8, 997-1016 (2008).

16. D. S. Balis et al., "Raman LIDAR and sunphotometric measurements of aerosol optical properties over Thessaloniki, Greece during a biomass burning episode," Atmos. Environ. 37(32), 4529-4538 (2003).

17. J. Sciare et al., "Long-term measurements of carbonaceous aerosols in the eastern mediterranean: evidence of long-range transport of biomass burning," Atmos. Chem. Phys. 8(18), 5551-5563 (2008).

18. F. Dahlkötter et al., "The Pagami creek smoke plume after long-range transport to the upper troposphere over Europe-aerosol properties and black carbon mixing state," Atmos. Chem. Phys. 14(12), 6111-6137 (2014).

19. K. M. Markowicz et al., "Study of aerosol optical properties during long-range transport of biomass burning from Canada to central Europe in July 2013," J. Aerosol Sci. 101, 156-173 (2016).

20. A. Ansmann et al., "The 16 April 2010 major volcanic ash plume over central Europe: earlinet LIDAR and AERONET photometer observations at Leipzig and Munich, Germany," Geophys. Res. Lett. 37(13), L13810 (2010).

21. A. Pietruczuk et al., "Eyjafjallajökull volcano ash observed over Belsk $\left(52^{\circ} \mathrm{N}, 21^{\circ} \mathrm{E}\right)$, Poland, in April 2010," Int. J. Remote Sens. 31(15), 3981-3986 (2010).

22. M. Campanelli et al., "Monitoring of Eyjafjallajökull volcanic aerosol by the new European skynet radiometers (ESR) network," Atmos. Environ. 48, 33-45 (2010).

23. K. M. Markowicz et al., "Remote sensing measurements of the volcanic ash plume over Poland in April 2010," Atmos. Environ. 48, 66-75 (2012).

24. P. N. Francis et al., "Retrieval of physical properties of volcanic ash using Meteosat: a case study from the 2010 Eyjafjallajökull eruption," J. Geophys. Res. Atmos. 117(D20), D00U09 (2012).

25. K. M. Markowicz et al., "Ceilometer retrieval of the boundary layer vertical aerosol extinction structure," J. Atmos. Oceanic Technol. 25(6), 928-944 (2008).

26. B. N. Holben et al., "Optical properties of aerosols from long term ground-based AERONET measurements," in Proc. ALPS99, WK1-O-19 (1999).

27. B. N. Holben et al., "AERONET's version 2.0 quality assurance criteria, remote sensing of atmosphere and clouds," Proc. SPIE 6408, 64080Q (2006).

28. T. F. Eck et al., "Measurements of irradiance attenuation and estimation of aerosol single scattering albedo for biomass burning aerosols in Amazonia," J. Geophys. Res. 103(D24), 31865-31878 (1998).

29. A. Smirnov et al., "Cloud-screening and quality control algorithms for the AERONET database," Remote Sens. Environ. 73(3), 337-349 (2000).

30. N. T. O'Neill et al., "Spectral discrimination of coarse and fine mode optical deph," J. Geophys. Res. 108(D17), 4559 (2003). 
31. A. F. Stein et al., "NOAA'S hysplit atmospheric transport and dispersion modeling system," Bull. Am. Meteorol. Soc. 96(12), 2059-2077 (2016).

32. A. Szkop et al., "Classification of aerosol over central europe by cluster analysis of aerosol columnar optical properties and backward trajectory statistics," Acta Geophys. 64(6), 2650 2676 (2016).

33. N. H. Robinson et al., "Source attribution of bornean air masses by back trajectory analysis during the OP3 project," Atmos. Chem. Phys. 11(18), 9605-9630 (2011).

34. A. Dvorská et al., "Kosetice, Czech Republic-ten years of air pollution monitoring and four years of evaluating the origin of persistent organic pollutants," Environ. Pollut. 156(2), 403408 (2008).

35. H. Scheifinger and A. Kaiser, "Validation of trajectory statistical methods," Atmos. Environ. 41(39), 8846-8856 (2007).

36. R. Wright et al., "MODVOLC: near-real-time thermal monitoring of global volcanism," J. Volcanol. Geotherm. Res. 135, 29-49 (2004).

37. D. J. Diner et al., "The value of multiangle measurements for retrieving structurally and radiatively consistent properties of clouds, aerosols, and surfaces," Remote Sen. Environ. 97, 495-518 (2005).

38. D. L. Nelson et al., "Stereoscopic height and wind retrievals for aerosol plumes with the MISR interactive explorer (MINX)," Remote Sens. 5(9), 4593-4628 (2013).

39. O. Dubovik et al., "Variability of absorption and optical properties of key aerosol types observed in worldwide locations," J. Atmos. Sci. 59(3), 590-608 (2002).

40. W. Rogula-Kozłowska et al., "A study on the seasonal mass closure of ambient fine and coarse dusts in Zabrze, Poland," Bull. Environ. Contam. Toxicol. 88(5), 722-729 (2012).

41. I. Stachlewska et al., "Ceilometer observations of the boundary layer over Warsaw, Poland," Acta Geophys. 60(5), 1386-1412 (2012).

42. P. R. Colarco et al., "Transport of smoke from Canadian forest fires to the surface near Washington, DC: injection height, entrainment, and optical properties," J. Geophys. Res. Atmos. 109(D6), D06203 (2004).

Biographies for the authors are not available. 